\title{
Role of diacylglycerols and calcium in the marsupial acrosome reaction
}

\author{
K. E. Mate ${ }^{*}$ and J. C. Rodger $\dagger$ \\ Department of Biological Sciences, The University of Newcastle, NSW Australia 2308
}

\begin{abstract}
Acrosomal loss was induced in marsupial spermatozoa by an intermediate of the phosphoinositide pathway. The diacylglycerol, 1,2-dioctanoyl-sn-glycerol $\left(\mathrm{DiC}_{g} ; 100 \mu \mathrm{mol} \mathrm{l}^{-1}\right)$ induced acrosomal loss in $70 \%$ of brushtail possum (Trichosurus vulpecula) spermatozoa and in $80 \%$ of tammar wallaby (Macropus engenii) spermatozoa. The $\mathrm{DiC}_{8}$-induced acrosomal loss was not enhanced by co-incubation with calcium ionophore $\mathrm{A} 23187$ and occurred in $\mathrm{Ca}^{2+}$. free medium and in the presence of the calcium chelator EGTA $\left(3 \mathrm{mmol}^{-1}\right)$. There was no evidence of uptake of ${ }^{45} \mathrm{Ca}^{2+}$ during the $\mathrm{DiC}_{8}$-induced acrosomal loss. Inhibitors of protein kinase $\mathrm{C}$ [1-(5-isoquinolinyl-sulfonyl)-2-methylpiperazine] and phospholipase $\mathrm{A}_{2}$ [dexamethasone] did not effect $\mathrm{DiC}_{8}$-induced acrosomal loss in wallaby spermatozoa. The phorbol ester, phorbol 12-myristate 13 -acetate, at a concentration of $10 \mu \mathrm{mol} \mathrm{l}^{-1}$ had no effect on possum spermatozoa and induced acrosomal loss in only $6 \%$ of wallaby spermatozoa. It appears that the $\mathrm{DiC}_{8}$-induced acrosome reaction is not mediated by activation of the phosphoinositide pathway and that extracellular calcium is not required for the membrane fusion event. As acrosomal loss was seen only at relatively high concentrations of diacylglycerol $\left(>50 \mu \mathrm{mol} \mathrm{l}^{-1}\right.$ ) and there is no evidence of involvement of other phosphoinositide intermediates or analogues, it is likely that its role is as a direct membrane fusogen.
\end{abstract}

\section{Introduction}

The marsupial acrosome is an unusually stable structure, which remains intact in the presence of high concentrations of divalent cations, calcium ionophore A23187 and cyclic nucleotides (Mate and Rodger, 1991). All of these treatments can induce the acrosome reaction in eutherian spermatozoa, although their effectiveness varies among species (Santos-Sacchi and Gordon, 1980; Shams-Borhan and Harrison, 1981; Fraser, 1984; Stock and Fraser, 1989; De Jonge et al., 1991). The stability of the marsupial acrosome appears to lie in the properties of the acrosomal membranes which resist damage by freeze-thawing without cryoprotectant and detergent treatment (Sistina et al., 1993a). Induced acrosomal loss was recently described in marsupial spermatozoa following exposure to high concentrations of the phosphoinositide pathway intermediates, the diacylglycerols, 1,2-dioctanoyl-sn-glycerol $\left(\mathrm{DiC}_{8}\right)$ and 1-oleoyl2-acetyl-sn-glycerol (OAG) (Sistina et al., 1993c). The manner of acrosome loss involved multiple point fusions of the plasma membrane and outer acrosomal membrane (Sistina et al., 1993c) and thus appeared similar to the physiological acrosome reaction of the spermatozoa of placental mammals (Barros et al., 1967; Yanagimachi and Noda 1970; Moore and Bedford, 1978).

The aim of this study was to examine the involvement of the phosphoinositide pathway in the regulation of the marsupial acrosome reaction. In general, activation of the phosphoinositide

*Present address: Laboratory of Radiobiology and Environmental Health, University of Califormia San Francisco, California, USA.

tReprint requests.

Received 20 October 1992. messenger system involves hydrolysis of polyphosphoinositides to generate the second messengers, inositol 1,4,5-triphosphate $\left(\mathrm{IP}_{3}\right)$ and diacylglycerol. Diacylglycerol operates as a messenger within the plane of the membrane to activate $\mathrm{a} \mathrm{Ca}^{2+}$ - and phospholipid-dependent protein kinase $\mathrm{C}(\mathrm{PKC})$, whereas $\mathrm{IP}_{3}$ is released into the cytoplasm to function as a second messenger by mobilizing intracellular calcium.

Phosphoinositides have been detected in the outer acrosomal membrane of boar spermatozoa (Berruti and Franchi, 1986) and a phospholipase $C$ specific for phosphoinositides has been described in human spermatozoa (Ribbes et al., 1987). Studies of the calcium ionophore A23187-induced acrosome reaction indicate that it is accompanied by polyphosphoinositide breakdown and a subsequent rise in phosphatidic acid $(\mathrm{PA}), \mathrm{IP}_{3}$, diacylglycerol and free arachidonic acid (Bennet et al., 1987; Harrison et al., 1990; Roldan and Harrison, 1990b; Roldan and Mollinedo, 1991). Although it has been reported that diacylglycerols and phorbol esters (modulators of PKC activity) stimulate the acrosome reaction in mouse spermatozoa (Lee et al., 1987), PKC is not detectable in ram, boar or hamster spermatozoa (Roldan and Harrison, 1988, 1990a). It has been suggested that in the absence of PKC in spermatozoa, the second messenger role of diacylglycerol in acrosomal exocytosis may be to activate a phospholipase $\mathrm{A}_{2}$ (Harrison and Roldan, 1990; Roldan and Harrison, 1990a; Roldan and Mollinedo, 1991). The fusogenic lysophospholipids subsequently produced by the action of phospholipase $A_{2}$ may then lead to the fusion of the plasma and outer acrosomal membranes.

This study examined whether the phosphoinositide pathway operates in marsupial spermatozoa during the $\mathrm{DiC}_{8}$-induced acrosome reaction.

Downloaded from Bioscientifica com at $04 / 26 / 2023$ 12:06:55AM 


\section{Materials and Methods}

\section{Animals and semen}

Adult male brushtail possums (Trichosurus vulpecula) were captured in the Newcastle area and housed as described by Rodger and Mate (1988) in a $14 \mathrm{~h}$ light:10 h dark cycle. Tammar wallabies (Macropus eugenii) were from the colony of the CSIRO Division of Wildlife and Ecology in Canberra and were housed as described by Mate and Rodger (1991). Work with protected species was licensed by the National Parks and Wildlife Service of New South Wales and animal experimentation had the approval of the University of Newcastle Animal Care and Ethics Committee.

Semen was collected by electroejaculation without dilution as described by Mate and Rodger (1991) from a pool of four possums and seven wallabies. At least seven days separated successive electroejaculations from any one animal. Individual sperm samples were used for each experimental replicate. The mean spermatozoa concentration during the experimental period for the possum ejaculates was $11.5 \times 10^{6}$ spermatozoa $\mathrm{ml}^{-1}$ and for the tammar was $135 \times 10^{6}$ spermatozoa ml $\mathrm{m}^{-1}$.

Possum and wallaby spermatozoa were washed by a swimup procedure as described by Mate and Rodger (1991). Wallaby semen was left at room temperature for 15-20 min to coagulate fully before washing (Sistina et al., 1993a). Ejaculates exhibiting poor motility or fewer than $5 \times 10^{6}$ spermatozoa $\mathrm{ml}^{-1}$ were discarded.

\section{Test solutions}

The agents to be tested were made up at ten times their final concentration in Eagle's minimum essential medium (EMEM; Cytosystems, Australia) containing 75 iu penicillin $\mathrm{ml}^{-1}$ and $0.05 \mathrm{mg}$ streptomycin $\mathrm{ml}^{-1}$ at $\mathrm{pH}$ 7.6. At the beginning of the incubation period the test solution was mixed 1:9 with the washed sperm suspension and incubated at $35^{\circ} \mathrm{C}$ in $5 \% \mathrm{CO}_{2}$ in air. All agents were obtained from the Sigma Chemical Co. (St Louis, MO). The agents used were: diacylglycerol-1,2dioctanoyl-sn glycerol $\left(\mathrm{DiC}_{8}\right)\left(50-100 \mu \mathrm{mol} \mathrm{l}^{-1}\right)$; calcium influx: $10 \mu \mathrm{mol}$ calcium ionophore A23187 ${ }^{-1}\left(\mathrm{Ca}^{2+}-\mathrm{Mg}^{2+}\right.$ mixed salts) in combination with $100 \mu \mathrm{moll}^{-1} \mathrm{DiC}_{8}$ incubated in the dark; protein kinase $\mathrm{C}(\mathrm{PKC})$ activator: phorbol 12-myristate 13-acetate $\left(0.01-10 \mu \mathrm{mol} \mathrm{l}^{-1}\right)$; PKC inhibitor: 1-(5-isoquinolinylsulfonyl)-2-methylpiperazine (ISMP) $\left(10-100 \mu \mathrm{mol} \mathrm{I}^{-1}\right)$ in combination with $100 \mu \mathrm{mol} \mathrm{l}^{-1} \mathrm{DiC}_{8}$; and phospholipase $\mathrm{A}_{2}\left(\mathrm{PLA}_{2}\right)$ inhibitor: dexamethasone $\left(1 \mathrm{mmol} \mathrm{l^{-1 }}\right)$ in combination with $100 \mu \mathrm{mol} \mathrm{DiC}_{8} \mathrm{l}^{-1}$.

\section{Effects of calcium concentration}

Wallaby and possum spermatozoa were washed by swim-up into either (i) EMEM; (ii) $\mathrm{Ca}^{2+}$-free EMEM, (iii) $\mathrm{Ca}^{2+}$ - and $\mathrm{Mg}^{2+}$-free Dulbecco's phosphate-buffered saline (PBS). The agents to be tested were made up at ten times their final concentration in the appropriate medium. At the beginning of the incubation period the test solution was mixed 1:9 with the washed sperm suspension and incubated at $35^{\circ} \mathrm{C}$ in $5 \% \mathrm{CO}_{2}$ in air. The agents tested were: $100 \mu \mathrm{mol} \mathrm{DiC}_{8} 1^{-1} ; 100 \mu \mathrm{mol} \mathrm{DiC}_{8}$ $\mathrm{l}^{-1}+3 \mathrm{mmol}$ EGTA I ${ }^{-1} ; 100 \mu \mathrm{mol} \mathrm{DiC}_{8} \mathrm{I}^{-1}+10 \mu \mathrm{mol}$ A23187 $1^{-1}$; and $100 \mu \mathrm{mol} \mathrm{DiC}_{8} \mathrm{l}^{-1}+10 \mu \mathrm{mol}$ A23187

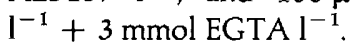

\section{Determination of calcium ion concentrations}

The concentration of calcium present in EMEM and $\mathrm{Ca}^{2+}$. free EMEM before and after washing of wallaby spermatozoa using the swim-up method was measured by atomic absorption spectroscopy. Samples of EMEM and $\mathrm{Ca}^{2+}$-free EMEM were used without modification for measurement before swim-up. To measure the calcium content of EMEM and $\mathrm{Ca}^{2+}$-free EMEM after swim-up, the sperm suspension was centrifuged at $1500 \mathrm{~g}$ for $15 \mathrm{~min}$ to pellet the spermatozoa, and the supernatant was removed for calcium determination. The calcium concentration of seminal plasma was also measured. Wallaby semen was collected into a graduated $50 \mathrm{ml}$ centrifuge tube and subsequently diluted 1:9 with $\mathrm{Ca}^{2+}$-free EMEM. The diluted semen was then centrifuged at $1500 \mathrm{~g}$ for $15 \mathrm{~min}$ to pellet the spermatozoa and the supernatant was used for calcium determination.

Standard solutions of calcium were prepared in $\mathrm{Ca}^{2+}$-free EMEM and ranged from 0 to $70 \mathrm{mg}^{-1}$. Calcium concentrations were determined using a Varian AA- 175 series atomic absorption spectrophotometer at the following settings: lamp current $3 \mathrm{~mA}$; acetylene nitrous oxide flame with a reducing red cone approximately $1.0-1.5 \mathrm{~cm}$ high; wavelength $422.7 \mathrm{~nm}$; and spectral band pass $0.1 \mathrm{~nm}$.

\section{Calcium uptake}

The uptake of ${ }^{45} \mathrm{Ca}^{2+}$ by wallaby spermatozoa was determined by a radiochemical procedure essentially as described by Simpson et al. (1987). The spermatozoa were adjusted to a concentration $\mathrm{I} \times 10^{7}$ spermatozoa $\mathrm{ml}^{-1}$ in $\mathrm{Ca}^{2+}$-free EMEM containing 75 iu penicillin $\mathrm{ml}^{-1}$ and $0.05 \mathrm{mg}$ streptomycin $\mathrm{ml}^{-1}$. ${ }^{45} \mathrm{CaCl}_{2}$ in EMEM was added to the sperm suspension to give a final concentration of $1 \mathrm{mmol} \mathrm{l}^{-1}$. The uptake of ${ }^{45} \mathrm{Ca}^{2+}$ by wallaby spermatozoa was measured in control EMEM, EMEM containing $100 \mu \mathrm{mol} \mathrm{DiC}_{8} \mathrm{I}^{-1}$ and high ionic strength ( $380 \mathrm{mOsmol}$ ) EMEM (HIS). Aliquots $(0.1 \mathrm{ml})$ of sperm suspension were taken with an automatic pipette at the times indicated in the results. The sperm samples were immediately filtered at a low pressure vacuum (2 psi) through glass fibre discs (Whatman/GFC, Clifton, NJ). The filters were washed five times with $3 \mathrm{ml}$ aliquots of EMEM that had been supplemented with $10 \mathrm{mmol}$ nonradioactive $\mathrm{CaCl}_{2} \mathrm{1}^{-1}$. The filters were then dried and counted in $3 \mathrm{ml}$ Liquiscint (National Diagnostics, USA) using a Hewlett-Packard Tri-Carb 1500 liquid scintillation analyser.

\section{Acrosome assessment}

Sperm samples were fixed for acrosomal assessment at the times indicated. Acrosomal status was scored for 100-200 spermatozoa per sample after Bryan's staining as described by Mate and Rodger (1991). Statistical analysis was by Student's $t$ test after square root transformation.

Downloaded from Bioscientifica.com at 04/26/2023 12:06:55AM 
Table 1. The concentration of calcium ions in the seminal plasma of tammar wallaby (Macropus eugenii) semen and culture media before and after swim-up

\begin{tabular}{lcc}
\hline & $\begin{array}{c}\text { Calcium concentration }(\mathrm{mmol} \mathrm{1} \\
\text { (mean } \pm \mathrm{SEM} ; n=3)\end{array}$ \\
\cline { 2 - 3 } Fluid & Before swim-up & After swim-up \\
\hline Seminal plasma & $1.41 \pm 0.21$ & nd \\
EMEM & $1.50 \pm 0.09$ & $1.50 \pm 0.30$ \\
$\mathrm{Ca}^{2+}$-free EMEM & $0.23 \pm 0.02$ \\
\hline
\end{tabular}

${ }^{2}$ Not detectable; nd: not determined; EMEM: Eagle's minimum essential medium.

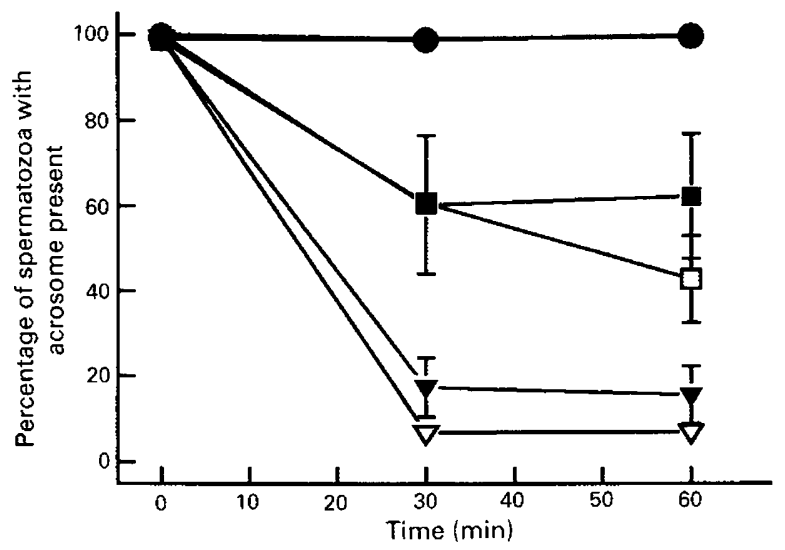

Fig. 1. The percentage of acrosome intact tammar wallaby (Macropus engenii) spermatozoa during incubation in Eagle's minimum essential medium (EMEM) (filled symbols) with 1,2-dioctanoyl-sn-glycerol $\left(\mathrm{DiC}_{\mathrm{g}}\right)$ at concentrations $0 \mu \mathrm{mol} \mathrm{l^{-1 }}(\mathbf{O}), 100 \mu \mathrm{mol} \mathrm{l}^{-1}(\mathbf{\nabla}), 100 \mu \mathrm{mol}$ $\mathrm{1}^{-1}+3 \mathrm{mmol}$ EGTA $\mathrm{I}^{-1}(\square)$ and in $\mathrm{Ca}^{2+}$-free EMEM (hollow symbols) with $\mathrm{DiC}_{8}$ at concentrations $0 \mu \mathrm{mol} \mathrm{l}^{-1}(\mathrm{O}$; obscured by filled circle), $100 \mu \mathrm{moll}^{-1}(\nabla), 100 \mu \mathrm{moll}^{-1}+3 \mathrm{mmol} \mathrm{EGTAl}^{-1}(\square)$. All points are means $\pm \operatorname{SEM} ; n=6$.

\section{Results}

\section{Calcium ion concentration of seminal plasma and test solutions}

The calcium concentration of seminal plasma obtained from wallabies by electroejaculation was approximately $57 \mathrm{mg} \mathrm{l}^{-1}$ or $1.41 \mathrm{mmol} \mathrm{l}^{-1}$. The calcium concentration of EMEM was $1.5 \mathrm{mmol} \mathrm{l^{-1 }}$, and did not change after the swim-up procedure (Table 1). Calcium-free EMEM did not contain measurable amounts of calcium; however, $0.23 \mathrm{mmol}$ calcium $\mathrm{I}^{-1}$ was detected after the swim-up procedure (Table 1 ).

\section{$\mathrm{DiC}_{8}$-induced acrosomal loss in calcium-free medium}

Acrosomal loss was induced in $80-90 \%$ of wallaby spermatozoa by $100 \mu \mathrm{mol} \mathrm{DiC}_{8} \mathrm{l}^{-1}$ (Fig. 1). There was no difference in the effectiveness of $\mathrm{DiC}_{8}$ in calcium-containing and calcium-free

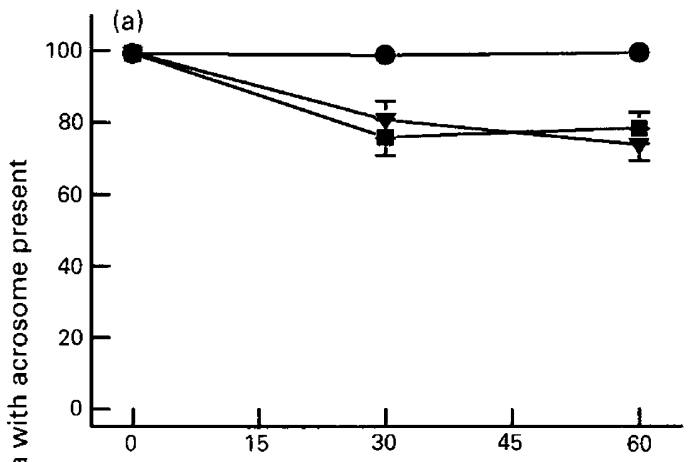

(b)

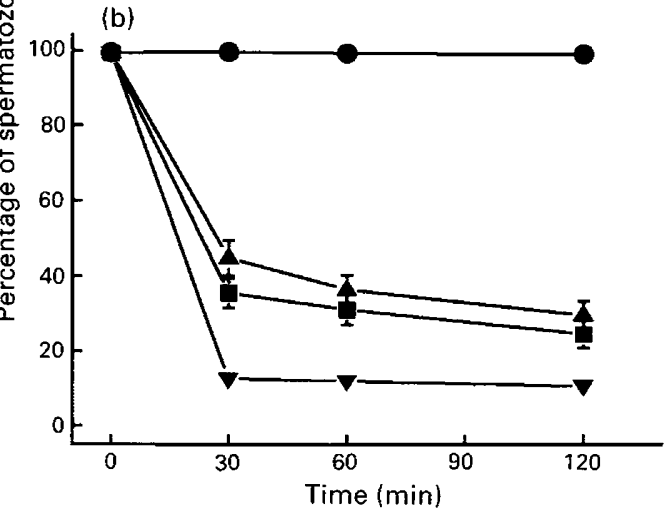

Fig. 2. The percentage of acrosome intact spermatozoa from the tammar wallaby (Macropus engenii) during incubation with 1,2-dioctanoyl-snglycerol $\left(\mathrm{DiC}_{8}\right)$ at concentrations of (a) $0 \mu \mathrm{mol} \mathrm{l}{ }^{-1}(\mathrm{O}), 50 \mu \mathrm{mol} \mathrm{l}^{-1}$ ( $\mathbf{V}$ ) or $50 \mu \mathrm{mol} \mathrm{^{-1 }}$ in combination with $10 \mu \mathrm{mol}$ calcium ionophore A23187 $1^{-1}(\boldsymbol{\square})$ and (b) $0 \mu \mathrm{mol} \mathrm{l^{-1 }}(\mathbf{O}), 100 \mu \mathrm{mol} \mathrm{l}^{-1}(\boldsymbol{\nabla}), 100 \mu \mathrm{mol}$ $1^{-1}+10 \mu \mathrm{mol}$ calcium ionophore $A 23187 \mathrm{l}^{-1}(\boldsymbol{\square})$ and $100 \mu \mathrm{mol}$

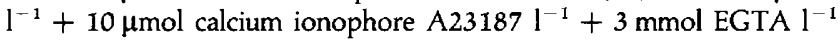
(A). All points are means $\pm \operatorname{SEM}$; (a) $n=6-10$ (b) $n=40$.

EMEM. Addition of $3 \mathrm{mmol}$ EGTA $^{-1}$ inhibited the actions of $\mathrm{DiC}_{8^{\prime}}$ so that significantly more spermatozoa remained acrosome intact $(P<0.05$ at 30 and $60 \mathrm{~min}$ in media with or without calcium). However, in the presence of EGTA, acrosomal loss occurred in approximately $40 \%$ of spermatozoa in both calcium-containing and calcium-free media, which was significantly greater than occurred in the control $(60 \mathrm{~min}$ EMEM: $P<0.05 ; 30 \mathrm{~min} \mathrm{Ca}^{2+}$-free EMEM: $P<0.01$ ).

Acrosomal loss in the presence of $\mathrm{DiC}_{8}$ and the calcium ionophore A23187

The presence of $50 \mu \mathrm{mol} \mathrm{DiC} \mathrm{I}^{-1}$ alone or in combination

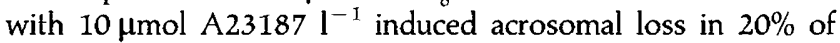
wallaby spermatozoa (Fig. 2a), significantly greater than occurred in the control $(P<0.01$ or 0.001$)$. One hundred $\mu \mathrm{mol}$ $\mathrm{DiC}_{8} \mathrm{l}^{-1}$ alone induced acrosomal loss in approximately $90 \%$ of spermatozoa after $30 \mathrm{~min}$ incubation (Fig. 2b), significantly more than occurred in the control $(P<0.0001)$. Around $60 \%$ of spermatozoa had lost their acrosome after treatment with either $100 \mu \mathrm{mol} \mathrm{DiC}_{8} 1^{-1}+10 \mu \mathrm{mol} \mathrm{A} 231871^{-1}\left(\mathrm{DiC}_{8}-\mathrm{A}\right)$ or

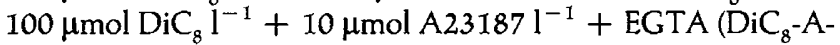
E) (Fig. 2b). This was significantly fewer than with $\mathrm{DiC}_{8}$ alone Downloaded from Bioscientifica.com at 04/26/2023 12:06:55AM 


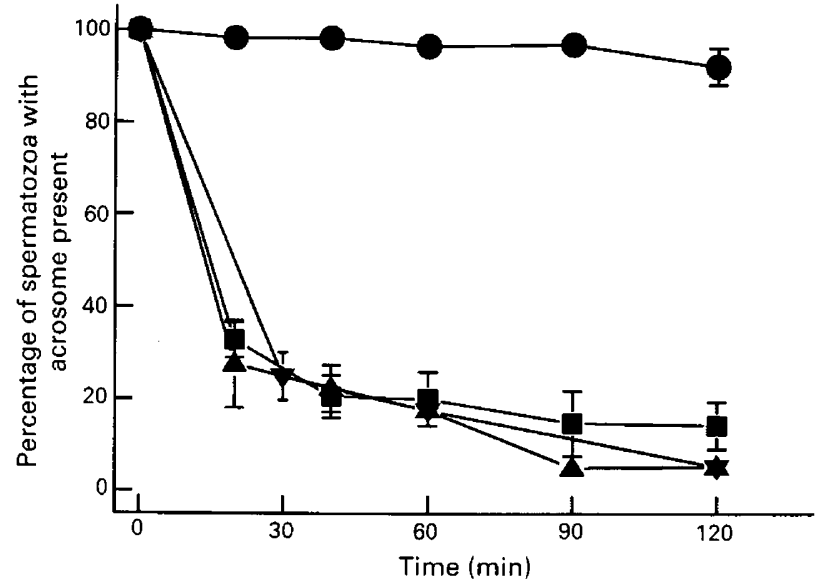

Fig. 3. The percentage of acrosome intact brushtail possum (Trichosurus vulpecula) spermatozoa during incubation in Eagle's minimum essential medium (EMEM) only (O), $100 \mu \mathrm{mol} \mathrm{1,2-dioctanoyl-sn-glycerol} 1^{-1}$ $\left(\mathrm{DiC}_{8} \boldsymbol{\Delta}\right) .100 \mu \mathrm{mol} \mathrm{DiC} \mathrm{l}^{-1}+10 \mu \mathrm{mol}$ calcium ionophore A23187 $\mathrm{l}^{-1}(\boldsymbol{\nabla})$ or, $100 \mu \mathrm{mol} \mathrm{DiC}_{8} \mathrm{l}^{-1}+10 \mu \mathrm{mol}$ calcium ionophore A23187 $1^{-1}+3 \mathrm{mmol} \mathrm{EGTA} \mathrm{I}^{-1}(\mathbf{G})$. All points are means \pm SEM; $n=4$.

$(P<0.01$ or 0.001$)$. There was no difference between $\mathrm{DiC}_{8}-\mathrm{A}$ and $\mathrm{DiC}_{8}-\mathrm{A}-\mathrm{E}$ in the induction of acrosomal loss.

In possum spermatozoa, $70-90 \%$ acrosomal loss occurred in response to $\mathrm{DiC}_{8}$ alone and to $\mathrm{DiC}_{8}$ in combination with A23187 and EGTA (Fig. 3). There were significantly fewer acrosome intact possum spermatozoa in the treated samples compared with the control $(P<0.01$ or 0.0001$)$. There was no difference in acrosomal loss between spermatozoa treated with $\mathrm{DiC}_{8}, \mathrm{DiC}_{8}+\mathrm{A} 23187\left(\mathrm{DiC}_{8}-\mathrm{A}\right)$ or $\mathrm{DiC}_{8}+\mathrm{A} 23187+\mathrm{EGTA}$ $\left(\mathrm{DiC}_{8}-\mathrm{A}-\mathrm{E}\right)$.

In wallaby spermatozoa, the effects of $\mathrm{DiC}_{8}+\mathrm{A} 23187$ $\left(\mathrm{DiC}_{8}-\mathrm{A}\right)$ and $\mathrm{DiC}_{8}+\mathrm{A} 23187+\mathrm{EGTA}\left(\mathrm{DiC}_{8}-\mathrm{A}-\mathrm{E}\right)$ on acrosomal loss were similar during incubation in EMEM (Fig. 4a), $\mathrm{Ca}^{2+}$-free EMEM (Fig. 4b) and PBS (Fig. 4c). Both $\mathrm{DiC}_{8}-\mathrm{A}$ and $\mathrm{DiC}_{8}-\mathrm{A}-\mathrm{E}$ induced significant acrosomal loss in wallaby spermatozoa in each of the media tested. Acrosomal loss (30$40 \%$ ) was statistically significant after 5 min incubation in $\mathrm{DiC}_{8}$ $A$ in both EMEM and after 10 min in PBS $(P<0.05)$. Results with $\mathrm{DiC}_{8}-\mathrm{A}$-E were more variable but achieved statistical significance after $30 \mathrm{~min}$ in EMEM, $20 \mathrm{~min}$ in $\mathrm{Ca}^{2+}$-free EMEM and $10 \mathrm{~min}$ in PBS $(P<0.05)$.

\section{Uptake of radiolabelled calcium during $\mathrm{DiC}_{8}$-induced acrosomal loss}

The presence of $100 \mu \mathrm{mol} \mathrm{DiC}_{8} 1^{-1}+10 \mu \mathrm{mol}$ calcium ionophore $\mathrm{A} 23187 \mathrm{I}^{-1}$ did not increase the uptake of ${ }^{45} \mathrm{Ca}^{2+}$ by wallaby spermatozoa (Fig. 5). The uptake of ${ }^{45} \mathrm{Ca}^{2+}$ was highest immediately after the addition of $\mathrm{DiC}_{8}+$ calcium ionophore A23187 but did not differ significantly from the control and had fallen to control values by $5 \mathrm{~min}$ of incubation. Less than $4 \mathrm{nmol}$ ${ }^{45} \mathrm{Ca}^{2+}$ were accumulated per $10^{8}$ spermatozoa during the incubation period.

Effect of PKC and PLA $A_{2}$ inhibitors on $\mathrm{DiC}_{8}$-induced acrosomal loss

The PKC inhibitor, 1-(5-isoquinolinyl-sulfonyl)-2-methylpiperazine (ISMP), did not inhibit the $\mathrm{DiC}_{8}$-induced acrosome

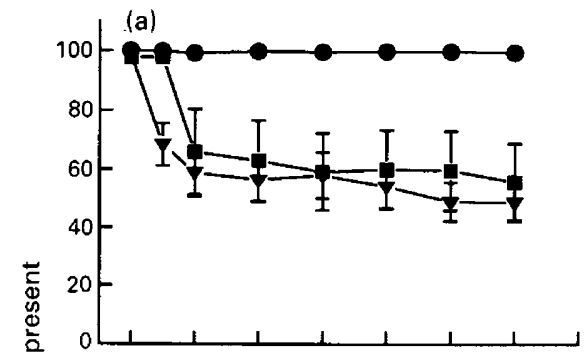

(b)
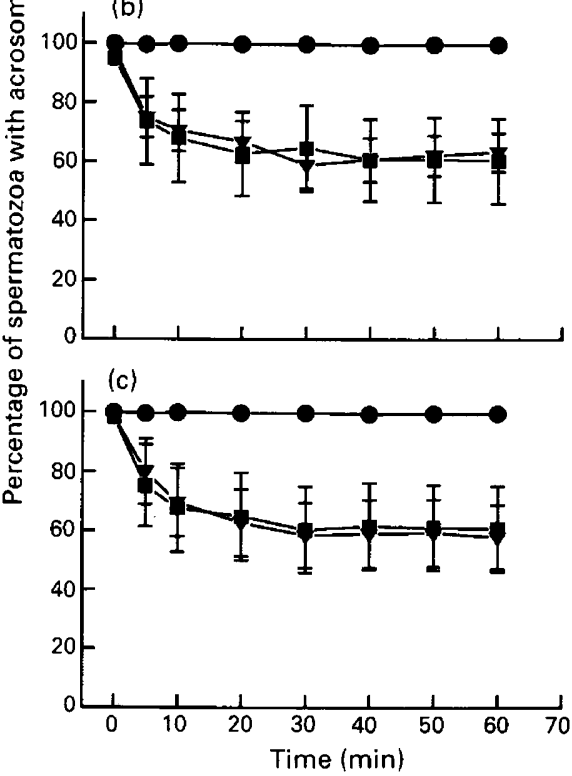

Fig. 4. The percentage of acrosome intact tammar wallaby (Macropus eugenii) spermatozoa during incubation in (a) Eagle's minimum essential medium (EMEM), (b) $\mathrm{Ca}^{2+}$-free EMEM or, (c) Dulbecco's phosphatebuffered saline (PBS) only (O) or with the addition of $100 \mu \mathrm{mol} \mathrm{1,2-}$ dioctanoyl-sn-glycerol $\mathrm{l}^{-1} \quad\left(\mathrm{DiC}_{8}\right)+10 \mu \mathrm{mol}$ calcium ionophore

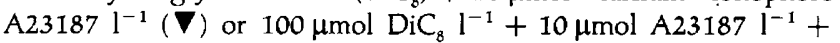
$3 \mathrm{mmol} \operatorname{EGTA~}^{-1}(\boldsymbol{\square})$. All points are means \pm SEM; $n=8-18$.

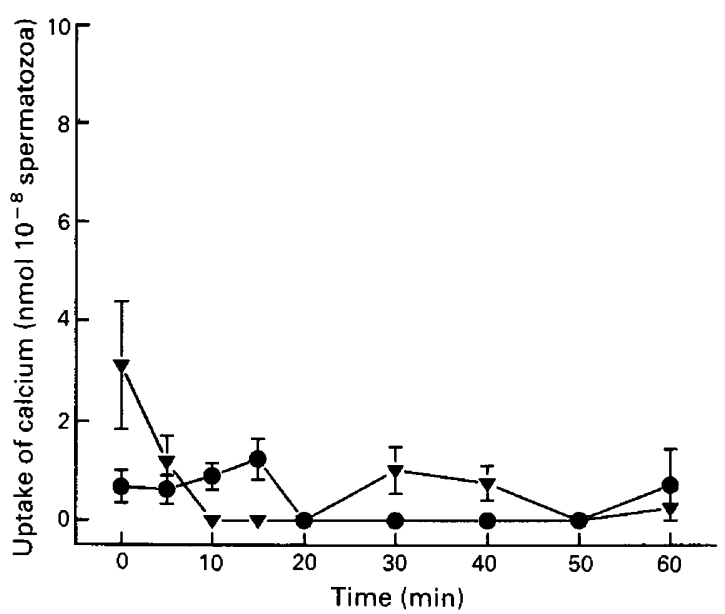

Fig. 5. The uptake of ${ }^{45} \mathrm{Ca}^{2+}$ by tammar wallaby (Macropus eugenii) spermatozoa during incubation in Eagle's minimum essential medium (EMEM) (O) or EMEM containing $100 \mu \mathrm{mol}$ 1,2-dioctanoyl-snglycerol $1^{-1}\left(\mathrm{DiC}_{8}\right)$ and $10 \mu \mathrm{mol} \mathrm{A23187} \mathrm{1}^{-1}(\boldsymbol{\nabla})$. All points are means $\pm \mathrm{SEM} ; n=5$.

Downloaded from Bioscientifica.com at 04/26/2023 12:06:55AM 
reaction in wallaby spermatozoa. The addition of $10 \mu \mathrm{mol}$ or $100 \mu \mathrm{mol}$ ISMP I ${ }^{-1}$ resulted in $97 \%(n=4)$ or $102 \%(n=4)$ of the acrosomal loss induced by $\mathrm{DiC}_{8}$ alone.

Addition of dexamethasone, an inhibitor of phospholipase $\mathrm{A}_{2}$, at a concentration of $1 \mathrm{mmol} \mathrm{l}^{-1}$, resulted in $111 \%(n=4)$ of the acrosomal loss induced by $\mathrm{DiC}_{8}$ alone.

\section{Effect of phorbol ester on the acrosomes of possum and wallaby spermatozoa}

The motility of possum and wallaby spermatozoa incubated in the presence of the phorbol ester, phorbol 12-myristate 13acetate (PMA), did not differ from that of control spermatozoa. PMA did not induce acrosomal loss in possum spermatozoa at the concentrations tested: $100 \pm 0 \%$ and $97.7 \pm 1.5 \%$ of possum spermatozoa remained acrosome intact after $3 \mathrm{~h}$ exposure to $0.01 \mu \mathrm{mol} \mathrm{l}^{-1}$ or $1.0 \mu \mathrm{mol} 1^{-1}$ PMA, respectively $(n=4)$. The percentage of acrosome-intact wallaby spermatozoa decreased to $94.2 \pm 1.3 \%$ after exposure to $10 \mu \mathrm{mol}$ PMA $1^{-1}$ for $3 \mathrm{~h}$, which was significantly lower than the control $(98.8 \pm 0.7 \% ; P<0.01)$. PMA did not induce acrosomal loss in wallaby spermatozoa at a concentration of $0.1 \mu \mathrm{mol}^{-1}$.

\section{Discussion}

Millimolar amounts of calcium are required for the acrosome reaction to occur in eutherian mammals; $1.8 \mathrm{mmol} \mathrm{l}^{-1}$ is the minimal requirement in mouse and human spermatozoa (Fraser, 1987; Stock and Fraser, 1989). Marsupial spermatozoa, however, appear able to undergo the acrosome reaction in the absence of extracellular calcium. The calcium ionophore A23187 does not induce the acrosome reaction (Mate and Rodger, 1991) and, in the present study, did not accelerate the rate of the $\mathrm{DiC}_{8}$-induced acrosome reaction in possum or wallaby spermatozoa. Indeed, $\mathrm{A} 23187$ inhibited the $\mathrm{DiC}_{8}$-induced acrosome reaction of wallaby spermatozoa, reducing the number of acrosome-reacted spermatozoa by approximately $50 \%$. The $\mathrm{DiC}_{8}$-induced acrosome reaction occurred in the absence of added calcium and in the presence of EGTA, and did not involve uptake of radiolabelled $\mathrm{Ca}^{2+}$. However, EGTA did reduce the number of wallaby spermatozoa undergoing the acrosome reaction in response to $\mathrm{DiC}_{8}$ by $50 \%$. These results indicate that if calcium is involved in the $\mathrm{DiC}_{8}$-induced marsupial acrosome reaction, that (i) only a very small amount of extracellular calcium is required or (ii) intracellular stores of calcium are sufficient.

The percentage of marsupial spermatozoa undergoing acrosomal loss in response to $\mathrm{DiC}_{8}$ was slightly higher in this study than was described by Sistina et al. (1993c). These differences may be attributable to a number of factors: the studies were carried out using different animals and batches of reagents, and at different times of the year, perhaps introducing seasonal effects in the semen samples. The $\mathrm{Ca}^{2+}$-independent $\mathrm{DiC}_{8}$ induced acrosome reaction of marsupial spermatozoa appears ultrastructurally as a true acrosome reaction involving point fusion between the plasma membrane and the outer acrosomal membrane (Sistina et al., 1993c). By contrast, other agents such as Triton $X-100$ and lysophosphatidylcholine have been demonstrated to result in degenerative acrosomal loss in marsupial spermatozoa (Sistina et al., 1993a, b). Spontaneous acrosomal loss in the absence of calcium has been reported in human spermatozoa, but was considered degenerative rather than due to a true acrosome reaction, although the ultrastructure of acrosome loss was not examined (White et al., 1990). Although calcium is required for membrane fusion in many types of cell and is of major importance in many processes of secretion that involve exocytosis, a requirement for calcium is not universal (Lucy, 1978). The fusion of erythrocytes induced by lysophosphatidylcholine or Sendai virus can occur in the absence of calcium (Howell and Lucy, 1969; Peretz et al., 1974; Hart et al., 1976) and a lysin obtained from the acrosome of abalone spermatozoa can induce liposome fusion in the absence of calcium (Hong and Vacquier, 1986).

Conventionally, the action of $\mathrm{DiC}_{8}$ is mediated through the activation of PKC. However, failure of the PKC inhibitor, ISMP, to prevent the $\mathrm{DiC}_{8}$-induced acrosome reaction in wallaby spermatozoa indicates that the activation of PKC is not involved in this case. Phorbol esters are more potent activators of PKC than are diacylglycerols (Bell, 1986; Leach and Blumberg, 1989), but in this study the phorbol ester, PMA, induced acrosomal loss in a very small number of spermatozoa, more suggestive of nonspecific effects on membrane structure. PKC has been detected in mouse spermatozoa (Kopf and Gerton, 1991) and induction of the acrosome reaction in mouse and human spermatozoa with phorbol esters and diacylglycerol is consistent with the involvement of PKC (Lee et al., 1987; De Jonge et al., 1989). However, potentially active PKC appears not to be present in ram or boar spermatozoa (Roldan and Harrison, 1988, 1990a). One of the difficulties in establishing a role for PKC is the existence of different types of PKC, each with different requirements for activation, kinase activities and binding affinities. Heterogeneity in the binding activity of PKC has been described in several types of cell (Konig et al., 1985; Dougherty and Niedel, 1986) and may occur in spermatozoa as evidenced by the markedly different effects of phorbol ester and DAG on capacitated and non-capacitated human and mouse spermatozoa (Lee et al., 1987; De Jonge et al., 1989). In addition, Roldan and Harrison (1990b) found that diacylglycerols alone could not induce acrosomal loss in ram spermatozoa but did accelerate the onset of the A23187-induced acrosome reaction. Leach and Blumberg (1989) suggested that the differences in the binding affinity of PKC were the result of modulation by changes in calcium concentration or phospholipid composition.

In ram spermatozoa the acrosome reaction inducing activity of diacylglycerols is mediated via the activation of $\mathrm{Ca}^{2+}$. dependent phospholipase A rather than PKC (Roldan and Harrison, 1988; Roldan and Mollinedo, 1991). Although calciumindependent PLA $A_{2}$ has been described (Kent and Vagelos, 1975; Pierik et al., 1988), the failure of the PLA, inhibitor, dexamethasone, to alter $\mathrm{DiC}_{8}$-induced acrosomal loss indicates that $\mathrm{DiC}_{8}$-induced acrosomal loss in marsupial spermatozoa was probably not due to stimulation of PLA .

In addition to their role in enzyme activation, diacylglycerols can play a more direct role in membrane fusion (Das and Rand, 1984; Dawson et al., 1984; Siegel, 1989). Diacylglycerols with long acyl chains effectively induce biomembrane fusion by reducing lamellar/inverted hexagonal phase transition temperature (Dawson et al., 1984; Siegel et al., 1989). Das and Rand Downloaded from Bioscientifica.com at 04/26/2023 12:06:55AM 
(1984) suggested that when diacylglycerol is incorporated into phospholipid bilayers its highly conical shape induces distortions and spreading apart of polar groups creating non-lamellar, hexagonal phases. Although such structural changes alone may not be sufficient for membrane fusion, they may enhance the access of proteins to the membrane hydrocarbon core and facilitate the interaction of enzymes with their phospholipid core (Dawson et al., 1984). The membrane transitions induced by DAG depend on the phospholipid species: they are most effective in phosphatidylethanolamine and phosphatidylcholine and least effective in phosphatidylserine (Das and Rand, 1984). The relatively high concentrations $\left(>50 \mu \mathrm{mol} \mathrm{l^{-1 } )}\right.$ of diacylglycerol required to induce the acrosome reaction in marsupial spermatozoa are consistent with its action as a direct membrane fusogen.

The mechanism of DAG-induced acrosome reaction in marsupial spermatozoa differs markedly from the eutherian acrosome reaction. Perhaps there is no absolute requirement for extracellular calcium. Inhibitor studies indicate that activation of protein kinase $C$ or phospholipase $A_{2}$ is probably not involved. It is suggested that the membrane fusion events observed in this study may be modulated by physical interaction of $\mathrm{DiC}_{8}$ with the sperm membranes and are probably not directly related to events in the phosphoinositide pathway.

Although $\mathrm{DiC}_{8}$-induced acrosome loss by marsupial spermatozoa mimicked the placental sperm acrosome reaction, it is not known whether the DAG-induced acrosome reaction in marsupials bears any relationship to the regulatory processes of the naturally occurring acrosome reaction.

This study was undertaken with the financial support of a grant to J. C. Rodger from the Australian Research Council. K. E. Mate was supported by a Australian Postgraduate Research Award. We are indebted to Dr Eduardo Roldan for his encouragement to pursue the diacylglycerols and for advice on their use and handling. Calcium determinations were performed using the facilities and assistance of members of the Department of Chemistry of the University of Newcastle.

\section{References}

Barros C, Bedford JM, Franklin LE and Austin CR (1967) Membrane vesiculation as a feature of the mammalian acrosome reaction Joumal of Cell Biology $\mathbf{3 4}$ CI-C5

Bell RM (1986) Protein kinase C activation by diacylglycerol second messengers Cell 45 631-632

Bennet PJ, Moatti JP, Mansat A, Ribbes H, Cayrac JC, Pontonnier F, Chap $\mathbf{H}$ and Douste-Blazy L (1987) Evidence for the activation of phospholipases during acrosome reaction of human sperm elicited by calcium jonophore A23187 Biochimica et Biophysica Acta 919 255-265

Berruti $G$ and Franchi E (1986) Calcium and polyphosphoinositides: their distribution in relation to the membrane changes occurring in the head of boar spermatozoa European Journal of Cell Biology 41 238-245

Das S and Rand RP (1984) Diacylglycerol causes major structural transitions in phospholipid bilayer membranes Biochemical and Biophysical Research Communications 124 491-496

Dawson RMC, Irvine RF, Bray J and Quinn PJ (1984) Long-chain unsaturated diacylglycerols cause a perturbation in the structure of phospholipid bilayers rendering them susceptible to phospholipase attack Biochemical and Biophysical Research Communications $125836-842$

De Jonge C, Mack SR and Zaneveld LJD (1989) Human sperm acrosome reaction regulation by modulators of diacylglycerol/protein kinase C pathway Biology of Reproduction Supplement $\mathbf{4 0} 148$
De Jonge CJ, Han HL, Lawrie H, Mack SR and Zaneveld LJD (1991) Modulation of the human sperm acrosome reaction by effectors of the adenylate cyclase/ cyclic AMP second-messenger pathway Journal of Experimental Zoology 258 $113-125$

Dougherty RW and Niedel JE (1986) Cytosolic calcium regulates phorbol diester binding affinity in intact phagocytes Joumal of Biological Chemistry 261 $4097-4100$

Fraser LR (1984) Mechanisms controlling mammalian fertilization. In Oxford Reviews of Reproductive Biology Vol. 6 pp 174-225 Ed. CA Finn. Clarendon Press, Oxford

Fraser LR (1987) Minimum and maximum extracellular $\mathrm{Ca}^{2+}$ requirements during mouse sperm capacitation and fertilization in vitro Journal of Reproduction and Fertility 81 77-89

Harrison RAP and Roldan ERS (1990) Phosphoinositides and their products in the mammalian sperm acrosome reaction Journal of Reproduction and Fertility Supplement 42 51 $\cdots 67$

Harrison RAP, Roldan ERS, Lander DJ and Irvine RF (1990) Ram spermatozoa produce inositol 1,4,5-trisphosphate but not inositol 1,3,4,5-tetrakisphosphate during the $\mathrm{Ca}^{2+} /$ ionophore-induced acrosome reaction Cellular Signalling 2 277-284

Hart CA, Fisher D, Hallinan T and Lucy JA (1976) Effects of calcium ions and the bivalent cation ionophore A23187 on the agglutination and fusion of chicken erythrocytes by Sendai virus Biochemical Journal 158 141-145

Hong K and Vacquier VD (1986) Fusion of liposomes induced by a cationic protein from the acrosome granule of abalone spermatozoa Biochemistry 25 543-549

Howell JI and Lucy JA (1969) Cell fusion induced by lysolecithin FEBS Letters 4 $147-150$

Kent $C$ and Vagelos PR (1975) Phospholipase A activity in plasma membranes from fusing muscle cells Federation Proceedings 34525 (Abstract)

Konig B, DiNitto PA and Blumberg PM (1985) Phospholipid and C.. $\mathrm{a}^{++}$ dependency of phorbol ester receptors Journal of Cell Chemistry 27 255-265

Kopf GS and Gerton GL (1991) The mammalian sperm acrosome and the acrosome reaction. In Elements of Mammalian Fertilization, Vol. 1 Basic Concepts pp 153-203 Ed. PM Wassarman. CRC Press, Boca Raton

Leach KL and Blumberg PM (1989) Tumour promoters, their receptors and their actions. In Inositol Lipids in Cell Signalling pp 179-205 Eds RH Michell, AH Drummond and CP Downes. Academic Press, London

Lee MA, Kopf GS and Storey BT (1987) Effects of phorbol esters and a diacylglycerol on the mouse sperm acrosome reaction induced by the zona pellucida Biology of Reproduction 36 617-627

Lucy JA (1978) Mechanisms of chemically induced fusion. In Membrane Fusion pp 267-304 Eds G Poste and GL Nicolson. Elsevier/North-Holland Biomedical Press, Amsterdam

Mate KE and Rodger JC (1991) Stability of the acrosome of the brush-tailed possum (Trichosurus vulpecula) and tammar wallaby (Macropus eugenii) in vitro and after exposure to conditions and agents known to cause capacitation or acrosome reaction of eutherian spermatozoa Journal of Reproduction and Fertility 91 41-48

Moore HDM and Bedford JM (1978) Ultrastructure of the equatorial segment of hamster spermatozoa during penetration of oocytes Joumal of Ultrastructure Research 62 110-117

Peretz, H., Toister Z, Laster Y and Loyter A (1974) Fusion of intact human erythrocytes and erythrocyte ghosts Joumal of Cell Biology 63 1-11

Pierik AJ, Nijssen JG, Aarsman AJ and Van den Bosch H (1988) Calciumindependent phospholipase $\mathrm{A}_{2}$ in rat tissue cytosols Biochimia et Biophysica Acta 962 345-353

Ribbes H, Plantavid M, Bennet PJ, Chap H and Douste-Blazy L (1987) Phospholipase $C$ from human sperm specific for phosphoinositides Biochimica et Biophysica Acta 919 245-254

Rodger JC and Mate KE (1988) A PMSG/GnRH method for the superovulation of the monovulatory brushtail possum (Trichosurus vulpecula) Journal of Reproduction and Fertility 83 885-891

Roldan ERS and Harrison RAP (1988) Absence of active protein kinase C in ram spermatozoa Biochemical and Biophysical Research Communications 155 901-906

Roldan ERS and Harrison RAP (1990a) Molecular mechanisms leading to exocytosis during the sperm acrosome reaction. In Fertilization in Mammals pp 179-196 Eds BD Bavister, J Cummins and ERS Roldan. Serono Symposia, Norwell

Roldan ERS and Harrison RAP (1990b) Diacylglycerol and phosphatidate production and the exocytosis of the sperm acrosome Biochemical and Biophysical Research Communications 172 8-15 Downloaded from Bioscientifica.com at 04/26/2023 12:06:55AM 
Roldan ERS and Mollinedo F (1991) Diacylglycerol stimulates the $\mathrm{Ca}^{2+}$ dependent phospholipase $A_{2}$ of ram spermatozoa Biochemical and Biophysical Research Communications 176 294-300

Santos-Sacchi J and Gordon M (1980) Induction of the acrosome reaction in guinea pig spermatozoa by cGMP analogues journal of Cell Biology $\mathbf{8 5}$ 798-803

Shams-Borhan G and Harrison RAP (1981) Production, characterization and use of ionophore-induced, calcium-dependent acrosome reaction in ram spermatozoa Gamete Research 4 407-432

Siegel DP, Banschbach J, Alford D, Ellens H, Lis LJ, Quinn PJ, Yeagle PL and Bentz J (1989) Physiological levels of diacylglycerols in phospholipid membranes induce membrane fusion and stabilize inverted phases Biochemistry $\mathbf{2 8}$ 3703-3709

Simpson AM, Swan MA and White IG (1987) Susceptibility of epididymal boar sperm to cold shock and protective action of phosphatidylcholine Gamete Research 17 355-373

Sistina Y, Lin M, Mate KE and Rodger JC (1993a) The unique stability of the marsupial sperm acrosomal membranes examined by unprotected freeze- thawing and treatment with the detergent Triton X-100 Reproduction Fertility and Development 5 1-14

Sistina Y, Lin M and Rodger JC (1993b) Lysophosphatidylcholine disrupts the acrosome of tammar wallaby (Macropus engenii) spermatozoa Molecular Reproduction and Development 35 277-284

Sistina Y, Lin M, Mate KE and Rodger JC (1993c) Induction of the marsupial sperm acrosome reaction in vitro by treatment with diacylglycerols Journal of Reproduction and Fertility $99335-341$

Stock CE and Fraser LR (1989) Divalent cations, capacitation and the acrosome reaction in human spermatozoa Journal of Reproduction and Fertility 87 463-478

White DR, Phillips DM and Bedford JM (1990) Factors affecting the acrosome reaction in human spermatozoa Journal of Reproduction and Fertility $9071-80$

Yanagimachi R and Noda YD (1970) Physiological changes in the post-nuclear cap region of mammalian spermatozoa: a necessary preliminary to the membrane fusion between sperm and egg cells Journal of Ultrastructure Research 31 486-493 